эксплуатации: система оснащена звуковым сопровождением, регистрируемые показатели выводятся на монитор персонального компьютера и представлены в виде пародонтологической карты. Последняя информативна как для врача, так и для пациента, но в большей степени ее реализация как графической схемы направлено на больного. Florida Probe предоставляет возможность динамического наблюдения на состоянием тканей пародонта путем сравнения пародонтальных карт пациента и сделать заключение об эффективности терапии [8].

Таким образом, курение является одним из основных местных факторов в развитии заболевания пародонта. Не только из-за содержания вредных, пагубно влияющих на ткани пародонта, но и из-за сухости и перегревания полости рта.

$$
* * *
$$

1. Кулыгина В.Н. Результаты исследования распространенности и структуры заболеваний пародонта у лиц молодого возраста / В.Н. Кулыгина, М.А. Мохаммад, Л.Л. Козлова // Украинский стоматологический альманах. - 2013. - №5. - С. 29-31.

2. Микляев С.В. Анализ распространенности хронических воспалительных заболеваний тканей пародонта / С.В. Микляев, О.М. Леонова, А.В. Сущенко // Современные проблемы науки и образования. - 2018. - № 2.; URL:

3. Сафров Д.А. Состояние органов и тканей полости рта на фоне табакокурения / Д.А. Сафров // European research. - 2017. - №5. - C. 87-89.

4. Юркевич В.Ю. Проблемы стоматологического здоровья у курильщиков в молодом возрасте / В.Ю. Юркевич // Здоровье - основа человеческого потенциала: проблемы и пути их решения. - 2013. - №1 - - С. 108-115.

5. Взаимосвязь состояния слизистой оболочки полости рта с количеством выделяемого угарного газа в выдыхаемом воздухе у табакозависимых пациентов / Ю.О. Солдатова, А.И. Булгакова, Х.Х. Ганцева, Ф.Р. Хисматуллина // Медицинский вестник Башкортостана. - 2016. - №2. - С. 40-43.

6. Lallier T.E. Greater Sensitivity of Oral Fibroblasts to Smoked Versus Smokeless Tobacco / T.E. Lallier, J.T. Moylan, E. Maturin // J Periodontol. - 2017. - №88. - P.1356-1365.

7. Кочиева И.В. Влияние табакокурения на микроциркуляцию в тканях пародонта / И.В. Кочиева, С.Н. Мкртчян, С.К. Хетагуров // Медико-фармацевтический журнал «Пульс». - 2015. - №1 - С. 57-58.

8. Круглова Н.В. Опыт использования компьютерной системы Florida Probe для диагностики воспалительных заболеваний пародонта / Н.В. Круглова, Л.М. Лукиных // Современные технологии в медицине. - 2012. №40. - С. 121-124.

\title{
Тимофеева Л.В. \\ Особенности вегетативной регуляции при первичной артериальной гипертензии у подростков
}

ФГБОУ ВО «Ярославский государственный медииинский университет» (Россия, Ярославль)

doi: 10.18411/trnio-11-2021-16

\section{Аннотация}

Цель: установить особенности вегетативной регуляции подростков с первичной артериальной гипертензией.

Материал и методы. Обследовано 60 подростков 12 - 17 лет с первичной артериальной гипертензией. Оценивали исходный вегетативный тонус (по сводным таблицам вегетативных проявлений), вегетативную реактивность (методом кардиоинтервалографии с ортостатической пробой), вегетативное обеспечение деятельности (клиноортостатическая проба по Шеллонгу).

Результаты. У подростков с первичной артериальной гипертензией регистрируется изолированная симпатикотония или смешанный исходный вегетативный тонус с преобладанием симпатикотонии. Наиболее частыми вариантами изменений вегетативного гомеокинеза являются избыточная реактивность и гипердиастолический вариант клиноортостатической пробы. Пациенты с таким вегетативным паттерном характеризуются наибольшей степенью нарушений суточного профиля артериального давления. 
Заключение. Особенности вегетативной регуляции сердечно-сосудистой системы оказывают значимое влияние на параметры суточного профиля артериального давления у подростков с первичной артериальной гипертензией.

Ключевые слова: первичная артериальная гипертензия, вегетативная регуляция, подростки.

\section{Abstract}

Objective: to establish the features of autonomic regulation in adolescents with primary arterial hypertension.

Material and methods. 60 adolescents aged 12-17 years with primary arterial hypertension were examined. The initial vegetative tone was evaluated (according to summary tables of vegetative manifestations), vegetative reactivity (by cardiointervalography with orthostatic test), vegetative activity support (clinoorthostatic Shellong test).

Results. Isolated simpatikotonia or mixed initial vegetative tone with predominance of simpatikotonia is registered in adolescents with primary arterial hypertension. The most frequent variants of changes in vegetative homeokinesis are excessive reactivity and hyperdiastolic variant of clinoorthostatic test. Patients with such a vegetative pattern are characterized by the highest degree of violations of the daily blood pressure profile.

Conclusion. Features of autonomic regulation of the cardiovascular system have a significant impact on the parameters of the daily blood pressure profile in adolescents with primary hypertension.

Keywords: primary arterial hypertension, autonomic regulation, adolescents.

Первичная артериальная гипертензия (ПАГ) представляет собой одну из наиболее актуальных проблем кардиологии. Не вызывает сомнения тот факт, что ее истоки этого заболевания лежат в детском возрасте. Многочисленные исследования указывают на существенный рост распространённости ПАГ среди подростков [1]. Известно, что стойкое повышение АД, особенно в дебюте ПАГ, в значительной степени обеспечивается нарушением нейрогуморальной регуляции сосудистого тонуса в виде активации симпатической вегетативной нервной системы [2]. Ряд гемодинамических эффектов, сопутствующих гиперсимпатикотонии, в частности, увеличение силы сердечных сокращений, тахикардия, повышение периферического сосудистого сопротивления вследствие вазоконстрикции, задержка катионов $\mathrm{Na}+$, способствуют артериальной гипертензии [4].

Цель работы: установить особенности вегетативной регуляции сердечно-сосудистой системы у подростков с первичной артериальной гипертензией.

\section{Материал и методы.}

Под нашим наблюдением находилось 60 подростков 12 - 17 лет, в том числе 34 юноши и 26 девушек, у которых в условиях специализированного кардиологического стационара верифицирована ПАГ.

Программа исследования включала определение исходного вегетативного тонуса (ИВТ), вегетативной реактивности (ВР) и обеспечения деятельности (ВОД). Тип ИВТ диагностировали по сводной клинической таблице вегетативных проявлений. ВР оценивали методом кардиоинтервалографии по отношению $\mathrm{ИН}_{2} / \mathrm{ИH}_{1}$ - индекса напряжения в ортостазе $\left(\mathrm{ИН}_{2}\right) \quad$ к его величине в клиноположении пациента $\left(\mathrm{ИН}_{1}\right)$, ВОД - с помощью клиноортостатической пробы по Шеллонгу. Полученные показатели функционального состояния вегетативной нервной системы сопоставляли с общепринятыми нормативами [5].

Статистическая обработка цифрового материала осуществлена с помощью программы StatPlus2009. Достоверность различий оценивали по критерию Манна - Уитни, относительных величин (\%) с помощью углового преобразования Фишера.

Результаты и их обсуждение. Оценка ИВТ показала, что подростки с ПАГ по этому признаку разделились на 2 подгруппы: часть из них $(\mathrm{n}=38)$ имела симпатикотонический 
ИВТ, в остальных случаях $(\mathrm{n}=22)$, кроме выраженного повышения симпатоадреналовой активности отмечалось также усиление тонуса парасимпатической системы. Таким образом, у этой подгруппы пациентов диагностирован смешанный ИВТ с преобладанием симпатикотонии.

Суточное мониторирование АД показало, что у подростков с изолированной симпатикотонией регистрируются более высокие значения систолического (САД) и диастолического (ДАД) АД, а также индексов времени артериальной гипертензии по сравнению с пациентами, имеющими смешанный ИВТ (таблица 1).

Таблица 1

Суточный профиль АД у подростков с первичной артериальной гипертензией в зависимости от типа исходного вегетативного тонуса $(M \pm m)$

\section{Показатели}

САД дневное, мм рт.ст.

ДАД дневное, мм рт.ст.

САД ночное, мм рт.cm.

ДАД ночное, мм рт.ст.

Индекс времени САД дневной, \%

Индекс времени ДАД дневной, \%

Индекс времени САД ночной, \%

Индекс времени ДАД ночной, \%
Тип исходного вегетативного тонуса

$\begin{array}{cc}\text { Симпатикотония } & \text { Смешанньий } \\ 137 \pm 2 & 132 \pm 2^{*} \\ 81 \pm 2 & 77 \pm 1 \\ 120 \pm 1 & 116 \pm 1^{*} \\ 66 \pm 1 & 65 \pm 1 \\ 52 \pm 2 & 42 \pm 3^{*} \\ 32 \pm 2 & 28 \pm 1^{*} \\ 42 \pm 2 & 34 \pm 1^{*} \\ 32 \pm 2 & 28 \pm 2\end{array}$

Примечание: *- $p<0,05$; ** - $p<0,01$.

Обнаружены различия ВР и ВОД, зависящие от типа ИВТ (таблица 2).

Таблица 2

Частота отдельных вариантов вегетативной реактивности и обеспечения деятельности у подростков с первичной артериальной гипертензией в зависимости от типа исходного вегетативного тонуса (\%)

Показатели

Нормальная ВР

Избыточная ВР

Недостаточная ВP

Нормальное ВОД

Гипердиастолический вариант ВОД

Примечание: ** - $p<0,01 ; * * *-p<0,005$.
Тип исходного вегетативного тонуса

Симпатикотония

0

75

25

27

73
Смешанный

$21 * *$

$48 *$

31

30

$32 * *$

При симпатикотоническом ИВТ значительно чаще встречалась избыточная ВР и гипердиастолический вариант ВОД.

Проанализировано влияние инвертированных вариантов ВР и ВОД на показатели суточного профиля АД у подростков с ПАГ (таблица 3).

Таблица 3

Суточный профиль АД у подростков с первичной артериальной гипертензией при различных вариантах вегетативной реактивности и обеспечения деятельности $(M \pm m)$

\section{Показатели}

САД дневное, мм рт.ст.

ДАД дневное, мм рт.ст.

САД ночное, мм рт.cm.

ДАД ночное, мм рт.ст.

Индекс времени САД дневной, \% Таким образом

Индекс времени САД ночной, \%

Индекс времени ДАД ночной, \%

Показатели

САД дневное, мм рт.cm.
Вариант вегетативной реактивности

$\begin{array}{cc}\text { Нормальная } & \text { Избыточная } \\ 135 \pm 2 & 134 \pm 2 \\ 79 \pm 2 & 84 \pm 1^{*} \\ 119 \pm 1 & 125 \pm 1^{* *} \\ 66 \pm 1 & 72 \pm 2^{*} \\ 48 \pm 2 & 69 \pm 3^{* *} \\ 32 \pm 2 & 35 \pm 1 \\ 42 \pm 2 & 72 \pm 7^{* *} \\ 32 \pm 2 & 38 \pm 2^{*}\end{array}$

Вариант вегетативного обеспечения деятельности Нормальный $134 \pm 2$
Гипердиастолический $139 \pm 2$ 
ДАД дневное, мм рт.ст.

САД ночное, мм рт.ст.

ДАД ночное, мм рт.cm.

Индекс времени САД дневной, \%

Индекс времени ДАД дневной, \%

Индекс времени САД ночной, \%

Индекс времени ДАД ночной, \%
$76 \pm 2$

$122 \pm 1$

$67 \pm 1$

$50 \pm 2$

$32 \pm 2$

$49 \pm 2$

$32 \pm 2$

$$
\begin{gathered}
81 \pm 1^{*} \\
124 \pm 1 \\
74 \pm 2^{*} \\
59 \pm 3^{*} \\
35 \pm 3 \\
70 \pm 9^{*} \\
36 \pm 2
\end{gathered}
$$

Примечание: * - $<<0,05$; ** - $p<0,01$.

Установлено, что избыточная вегетативная реактивность и гипердиастолический вариант клиноортостатической пробы сопровождаются большей степенью нарушения суточного профиля АД по сравнению с пациентами, имеющими нормальные значения указанных параметров вегетативного гомеокинеза.

В ряде исследований было показано, что ирритация симпатоадреналовой системы, увеличивая сосудистое сопротивления, способствует стабилизации АД на высоких цифрах. Усиление тонуса холинергической системы оказывает сдерживающее воздействие на показатели АД $[2,4,5]$.

Заключение. Особенности вегетативной регуляции сердечно-сосудистой системы оказывают значимое влияние на параметры суточного профиля АД у подростков с первичной артериальной гипертензией. Наиболее высокие цифры АД и индексы времени артериальной гипертензии наблюдаются у пациентов с изолированной симпатикотонией, избыточной вегетативной реактивностью и гипердиастолическим вариантом клиноортостатической пробы.

$$
* * *
$$

1. Александров А.А., Кисляк О.А., Леонтьева И.В. от имени экспертов. Клинические рекомендации. Диагностика, лечение и профилактика артериальной гипертензии у детей и подростков // Системные гипертензии. - 2020. -Т. 17. - № 2. - С. 7-35.

2. Спивак Е.М., Печникова Н.В. Особенности вегетативной регуляции сердечно-сосудистой системы при первичной артериальной гипертензии у подростков // Ярославский педагогический вестник. - 2012. - Т. 3. № 3. - С. 155- 158 .

3. Конради А.О. Вегетативная нервная система при артериальной гипертензии и сердечной недостаточности: современное понимание патофизиологической роли и новые подходы к лечению // Российский кардиологический журнал. - 2013. - Т. 102. - № 4. - 52-63.

4. Спивак Е.М., Курбанова И.М. Особенности вегетативной регуляции и функциональное состояние сердечнососудистой системы у юных спортсменов // Вопросы практической педиатрии. - 2008. - Т. 3. - №. - С. 20-23.

5. Спивак Е.М., Нежкина Н.Е. Особенности адаптации сердечно-сосудистой системы к нагрузке у юных спортсменов с различными типами вегетативной регуляции // Спортивная медицина: наука и практика. 2014. - № 1. - C. 32-36.

Травенко Е.Н., Породенко В.А., Меликян М.Г. Антенатальная гибель плода в практике судебно-медицинского эксперта

\section{Аннотация}

Проведен ретроспективный анализ результатов судебно-медицинского исследования погибших антенатально плодов и последов. Проанализированы факты риска и причины антенатальной гибели плода. Установлено, что ведущими причинами смерти в антенатальном периоде явилась острая и хроническая плацентарная недостаточность (60\%). Посмертное исследование плодов и плаценты позволяет более точно идентифицировать причину смерти.

Ключевые слова: антенатальная гибель плода, клинико-морфологический анализ факторов риска, судебно-медицинское исследование плода. 